\title{
HUBUNGAN ANTARA HIPERTENSI DENGAN PENURUNAN FUNGSI KOGNITIF DI PUSKESMAS SAMALANTAN, KALIMANTAN BARAT
}

\author{
Lasta Arshinta, Ivo Ariandi, Sholehuddin Munajjid
}

Puskesmas Samalantan, Bengkayang, Kalimantan Barat, Indonesia

Diterima 11 Agustus 2017

Disetujui 5 Mei 2018

Publikasi 21 Mei 2018

Korespondensi: arshintalasta@gmail.com
Cara merujuk artikel ini: Arshinta (et al). 2018. Hubungan Antara Hipertensi dengan Penurunan Fungsi Kognitif di Puskesmas Samalantan, Kalimantan Barat. Callosum Neurology Journal 1(2): 41-46. DOI: https://doi.org/10.29342/cnj.vli2.24

\begin{abstract}
ABSTRAK
Latar Belakang: Hipertensi kronis dapat mengakibatkan gangguan fungsi kognitif. Penelitian berkaitan dengan masalah ini masih belum banyak dilakukan di Indonesia.

Tujuan: Untuk mengetahui hubungan hipertensi terhadap penurunan fungsi kognitif pasien di wilayah kerja Puskesmas Samalantan, Kalimantan Barat.

Metode: Penelitian observasional-analitik dengan desain penelitian potong lintang. Jumlah sampel sebanyak 36 responden, dengan metode consecutive sampling. Kuesioner dan pemeriksaan Mini-Mental State Examination (MMSE) pasien hipertensi selama bulan November-Desember 2016.
\end{abstract}

Hasil: 11,76\% pasien dengan hipertensi grade 1, $7,7 \%$ pasien dengan hipertensi grade II, dan $50 \%$ pasien dengan krisis hipertensi mengalami gangguan fungsi kognitif. Uji Pearson menunjukkan hipertensi memiliki pengaruh terhadap penurunan fungsi kognitif dan bermakna secara signifikan $(\mathrm{p}<0.05)$.

Simpulan: Terdapat hubungan antara hipertensi dengan terjadinya penurunan fungsi kognitif. Tetapi terdapat variabel-variabel lain yang dapat mempengaruhi hasil penelitian.

Kata Kunci: Fungsi kognitif, hipertensi, MiniMental State Examination

\section{ABSTRACT}

Background: Chronic high blood pressure could cause cognitive function impairment. Nevertheless, in Indonesia, studies related to this issue are not much done yet.

Purpose: To determine hypertension toward patient's cognitive function decline in Samalantan Public Health Center, West Kalimantan

Method: This was an observational-analytical study with cross-sectional approach. There were 36 patients selected by consecutive sampling. A structured questionnaire and MMSE scoring given to hypertensive patients from November-December 2016.
Result: $11,76 \%$ patients with grade I hypertension, $7,7 \%$ patients with grade II hypertension, and $50 \%$ patients with hypertensive crisis had cognitive function decline. Hypertension had significant effect on cognitive function decline $(\mathrm{p}<0.05 \%)$.

Conclusion: Hypertension is significantly associated with cognitive function decline. However, there are other variables those can affect the outcome of this study.

Keywords: Cognitive function, hypertension, Mini-Mental State Examination 


\section{Latar Belakang}

Hipertensi memerlukan penanggulangan yang baik karena dapat menyebabkan kerusakan organ target seperti otak, jantung, ginjal, dan mata. Hipertensi meningkatkan risiko dua kali lipat terjadinya penyakit jantung koroner dan tiga kali lipat terjadinya gagal jantung dan stroke. ${ }^{1}$ Data dari World Health Organization (WHO) dan The International Society of Hypertension (ISH) menunjukkan saat ini terdapat 600 juta penderita hipertensi di seluruh dunia, dengan 3 juta diantaranya meninggal dunia setiap tahunnya. Tujuh dari setiap 10 penderita tidak mendapatkan pengobatan secara adekuat. ${ }^{2}$

Hipertensi merupakan kondisi yang kompleks. Kondisi ini berupa peningkatan menetap tekanan darah yang penyebabnya tidak diketahui (hipertensi primer) maupun yang penyebabnya berhubungan dengan penyakit lain (hipertensi sekunder). Eighth Joint National Committee (JNC-8) membagi klasifikasi tekanan darah orang dewasa sebagai klasifikasi normal (tekanan darah sistolik di bawah $120 \mathrm{mmHg}$ dan tekanan darah diastolik di bawah $80 \mathrm{mmHg}$ ), pre-hipertensi (tekanan darah sistolik berkisar dari 120-139 $\mathrm{mmHg}$ atau tekanan darah diastolik berkisar dari $80-89 \mathrm{mmHg}$ ), hipertensi derajat I (tekanan darah sistolik berkisar dari 140$159 \mathrm{mmHg}$ atau tekanan darah diastolik berkisar dari 90-99 $\mathrm{mmHg}$ ), dan hipertensi derajat II (tekanan darah sistolik lebih dari atau sama dengan $160 \mathrm{mmHg}$ atau tekanan darah diastolik lebih dari atau sama dengan $100 \mathrm{mmHg}){ }^{3}$ Klasifikasi tambahan berupa krisis hipertensi, yaitu peningkatan tekanan darah yang berat, yaitu tekanan darah sistolik di atas $180 \mathrm{mmHg}$ atau tekanan darah diastolik di atas $120 \mathrm{mmHg}$, dengan atau tanpa gangguan fungsi target organ seperti sindrom koroner akut, gagal jantung akut dekompensasi, ensefalopati, perdarahan intraserebral, dan gagal ginjal akut. Krisis hipertensi terbagi menjadi hipertensi urgensi, di mana terjadi peningkatan tekanan darah $>180 / 120$ $\mathrm{mmHg}$ namun tidak terdapat gangguan target organ, dan hipertensi emergensi, yaitu peningkatan tekanan darah $>180 / 120 \mathrm{mmHg}$ dan disertai gangguan target organ. ${ }^{4}$ Diperkirakan pada tahun 2025, kejadian hipertensi akan meningkat menjadi $60 \%$ dari seluruh populasi, yaitu sekitar 1,56 miliar jiwa. Data Riset Kesehatan Dasar (Riskesdas) Badan Penelitian dan Pengembangan Kesehatan (Balitbangkes) menunjukkan kejadian hipertensi di Indonesia secara nasional mencapai 31,7\%.

Terdapat hubungan antara peningkatan tekanan darah dengan penurunan fungsi kognitif dengan mekanisme yang belum jelas diketahui. Diduga hipertensi dan kronis akan mengakibatkan gangguan fungsi kognitif yang dapat berlanjut menjadi demensia vaskular dibandingkan dengan individu yang normotensi. ${ }^{6}$ Hipertensi menyebabkan perubahan adaptif pada pembuluh darah serebral dan mencetuskan terjadinya hipoperfusi, kerusakan substansia alba, hingga gangguan mikrovaskular. Hipertensi menyebabkan terjadinya arteriosklerosis pada jaringan serebral yang berhubungan dengan terjadinya gangguan kognitif. Kapiler dan arteriol jaringan serebral akan mengalami penebalan dinding akibat deposisi hyalin dan proliferasi tunika intima yang menyebabkan penyempitan diameter lumen dan peningkatan resistensi pembuluh darah. Hal tersebut akan menyebabkan penurunan perfusi jaringan serebral yang dapat menyebabkan iskemia dan infark lakunar jaringan serebral, khususnya substansia alba serebri. ${ }^{7}$ Hipertensi meningkatkan risiko kerusakan sistem regulasi neurovaskuler yang merupakan komponen penting dalam mengatur fungsi motorik dan fungsi kognitif. ${ }^{8}$

Beberapa penelitian sebelumnya telah mengungkapkan bahwa hipertensi jangka panjang dapat menyebabkan penurunan fungsi kognitif yang mengganggu kualitas hidup penderita. Namun penelitian serupa di Indonesia masih belum banyak dilakukan, terutama di wilayah kerja Puskesmas Samalantan, Kabupaten Bengkayang, Kalimantan Barat.

\section{Metode Penelitian}

Penelitian ini dimulai sejak bulan NovemberDesember 2016. Metode penelitian yang digunakan adalah penelitian deskriptif analitik dengan jenis korelasi dan desain penelitian potong lintang. Pengukuran tekanan darah sesuai kriteria JNC-8 terhadap seluruh pasien yang berusia $\geq 45$ tahun yang berobat ke Puskesmas Samalantan. Kriteria inklusi pada penelitian ini adalah pria dan/atau wanita dengan usia $\geq 45$ tahun, menderita hipertensi 
atau memiliki riwayat hipertensi, pendidikan minimal sekolah dasar (SD) atau sederajat. Kriteria eksklusi dalam penelitian ini adalah apabila pasien menolak untuk diikutsertakan dalam penelitian, pasien tidak dapat menyelesaikan tes MMSE, pasien dengan gangguan psikiatri, retardasi mental, riwayat stroke, tumor otak, trauma kepala, menderita infeksi sistem saraf pusat, epilepsi, penyakit Parkinson, riwayat mendapat terapi obat penenang, dan pasien dengan depresi. Sebanyak 36 subjek penelitian telah dipilih dengan menggunakan teknik consecutive sampling. Alur penelitian dibuat dalam kerangka yang terdapat dalam gambar 1 . Seluruh subjek penelitian diminta persetujuannya untuk diikutsertakan dalam penelitian dengan informed consent tertulis.

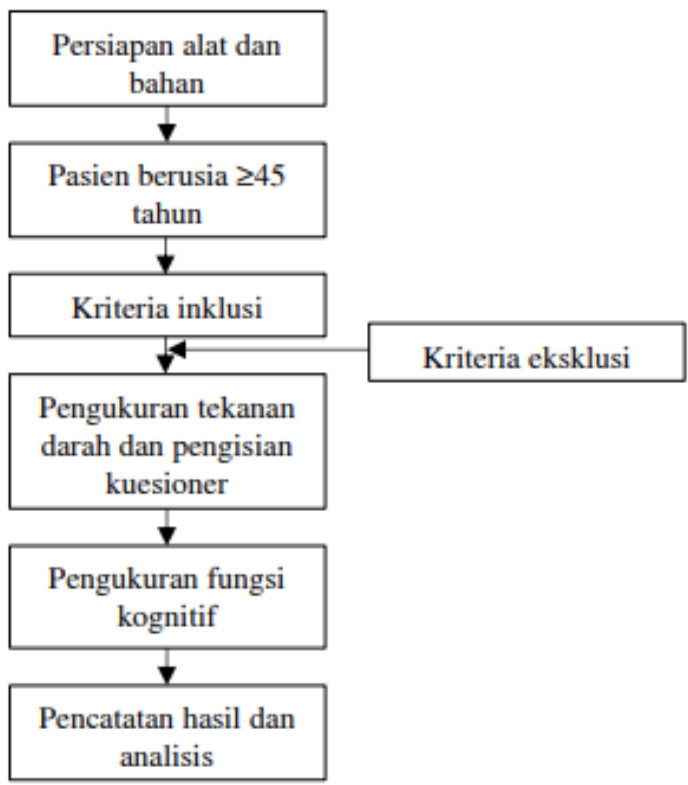

Gambar 1. Alur Penelitian

\section{Hasil Penelitian}

Sebanyak 36 responden dengan karakteristik sosiodemografis responden ditunjukkan pada tabel 1. Selanjutnya fungsi kognitif pasien ditabulasikan dengan karakteristik responden. Didapatkan fungsi kognitif normal pada 30 orang pasien $(83,3 \%)$ dengan skor MMSE > 24, sedangkan sebanyak 6 pasien $(16,7 \%)$ memiliki gangguan fungsi kognitif ringan (skor MMSE 18-23). Tidak terdapat pasien yang memiliki gangguan fungsi kognitif berat (hasil MMSE $\leq 17$ ). Sebanyak 17 pasien memiliki riwayat hipertensi grade I dengan 2 orang di antaranya $(11,76 \%)$ memiliki fungsi kognitif yang terganggu. Sebanyak 13 pasien mengalami hipertensi grade II dengan 1 orang di antaranya $(7,7 \%)$ mengalami gangguan fungsi kognitif. Terdapat 6 pasien yang mengalami krisis hipertensi dengan 3 orang diantaranya (50\%) mengalami gangguan fungsi kognitif.

\section{Pembahasan}

Beberapa faktor berhubungan dengan penurunan fungsi kognitif. Secara statistik, hipertensi memiliki pengaruh terhadap penurunan fungsi kognitif dan bermakna secara signifikan $(\mathrm{p}<0.05)$. Hasil penelitian ini menunjukkan frekuensi gangguan fungsi kognitif pada pasien dengan hipertensi yang serupa dengan beberapa penelitian sebelumnya. Terdapat hubungan antara kondisi hipertensi terhadap kejadian gangguan fungsi kognitif yang dialami. $^{9}$

Tabel 1. Karakteristik Responden

\begin{tabular}{|c|c|}
\hline Variabel & n $(\%)$ \\
\hline \multicolumn{2}{|l|}{ Usia } \\
\hline $45-50$ tahun & $15(41,7)$ \\
\hline $51-55$ tahun & $11(30,6)$ \\
\hline 56-60 tahun & $7(19,4)$ \\
\hline $61-65$ tahun & $2(5,6)$ \\
\hline$>65$ tahun & $1(2,8)$ \\
\hline \multicolumn{2}{|l|}{ Jenis kelamin } \\
\hline Perempuan & $21(58,3)$ \\
\hline Laki-laki & $15(41,7)$ \\
\hline \multicolumn{2}{|l|}{ Riwayat pendidikan } \\
\hline Tidak tamat SD & $4(11,1)$ \\
\hline Tamat SD & $16(44,4)$ \\
\hline Tamat SMP & $12(33,3)$ \\
\hline Tamat SMA & $1(2,8)$ \\
\hline Perguruan tinggi & $3(8,3)$ \\
\hline \multicolumn{2}{|l|}{ Pekerjaan } \\
\hline Tidak bekerja & $11(30,6)$ \\
\hline Bekerja & $25(69,4)$ \\
\hline \multicolumn{2}{|l|}{ Perilaku merokok } \\
\hline Tidak merokok & $23(63,9)$ \\
\hline Merokok & $13(36,1)$ \\
\hline \multicolumn{2}{|l|}{ Aktivitas olahraga } \\
\hline Tidak rutin olahraga & $35(97,2)$ \\
\hline Rutin olahraga & $1(2,8)$ \\
\hline \multicolumn{2}{|l|}{ Tingkat fungsi kognitif } \\
\hline Normal & $30(83,3)$ \\
\hline Gangguan fungsi kognitif ringan & $6(16,7)$ \\
\hline Gangguan fungsi kognitif berat & $0(0)$ \\
\hline
\end{tabular}


Faktor usia berhubungan dengan kejadian Hubungan jenis kelamin dengan penurunan fungsi penurunan fungsi kognitif seseorang. Semakin kognitif menunjukkan individu wanita lebih meningkat usia maka penurunan fungsi kognitif berisiko mengalami penurunan fungsi kognitif yang akan semakin nyata. Penelitian yang dipublikasikan disebabkan adanya perubahan level hormon seks sebelumnya menunjukkan hubungan positif antara meningkatnya usia dengan menurunnya fungsi kognitif. ${ }^{10,11}$ endogen. Rendahnya level estradiol dalam tubuh telah dikaitkan dengan penurunan fungsi kognitif umum dan memori verbal. ${ }^{12,13}$

Tabel 2. Distribusi frekuensi fungsi kognitif dengan karakteristik responden

\begin{tabular}{|c|c|c|c|}
\hline & $\begin{array}{c}\text { Fungsi Kognitif Normal } \\
\text { Frekuensi }(\%)\end{array}$ & $\begin{array}{c}\text { Fungsi Kognitif Terganggu } \\
\text { Frekuensi }(\%)\end{array}$ & Total \\
\hline \multicolumn{4}{|l|}{ Hipertensi } \\
\hline Pre-hipertensi & $0(0)$ & $0(0)$ & 0 \\
\hline Hipertensi grade I & $15(88,2)$ & $2(11,7)$ & 17 \\
\hline Hipertensi grade II & $12(92,3)$ & $1(7,7)$ & 13 \\
\hline Krisis hipertensi & $3(50)$ & $3(50)$ & 6 \\
\hline Total & 30 & 6 & 36 \\
\hline \multicolumn{4}{|l|}{ Jenis kelamin } \\
\hline Laki-laki & $13(86,7)$ & $2(13,3)$ & 15 \\
\hline Perempuan & $17(80,9)$ & $4(19,1)$ & 21 \\
\hline Total & 30 & 6 & 36 \\
\hline \multicolumn{4}{|l|}{ Usia } \\
\hline 45-50 tahun & $14(93,3)$ & $1(6,7)$ & 15 \\
\hline 51-55 tahun & $11(100)$ & $0(0)$ & 11 \\
\hline 56-60 tahun & $4(57,1)$ & $3(42,9)$ & 7 \\
\hline $61-65$ tahun & $1(50)$ & $1(50)$ & 2 \\
\hline$>65$ tahun & $0(0)$ & $1(100)$ & 1 \\
\hline Total & 30 & 6 & 36 \\
\hline \multicolumn{4}{|l|}{ Tingkat Pendidikan } \\
\hline Tidak tamat SD & $0(0)$ & $4(100)$ & 4 \\
\hline Tamat SD & $15(93,7)$ & $1(6,3)$ & 16 \\
\hline Tamat SMP & $11(91,6)$ & $1(8,4)$ & 12 \\
\hline Tamat SMA & $1(100)$ & $0(0)$ & 1 \\
\hline Perguruan tinggi & $3(100)$ & $0(0)$ & 3 \\
\hline Total & 30 & 6 & 36 \\
\hline \multicolumn{4}{|l|}{ Pekerjaan } \\
\hline Tidak bekerja & $7(63,6)$ & $4(36,4)$ & 11 \\
\hline Bekerja & $23(92)$ & $2(8)$ & 25 \\
\hline Total & 30 & 6 & 36 \\
\hline \multicolumn{4}{|l|}{ Perilaku Merokok } \\
\hline Tidak merokok & $20(86,9)$ & $3(13,1)$ & 23 \\
\hline Merokok & $10(76,9)$ & $3(23,1)$ & 13 \\
\hline Total & 30 & 6 & 36 \\
\hline \multicolumn{4}{|l|}{ Aktivitas Olahraga } \\
\hline Tidak rutin & $29(82,8)$ & $6(17,2)$ & 35 \\
\hline Rutin olahraga & $1(100)$ & $0(0)$ & 1 \\
\hline Total & 30 & 6 & 36 \\
\hline
\end{tabular}



Pengaruh penurunan fungsi kognitif juga ditunjukkan oleh tingkat pendidikan serta status pekerjaan responden. Peneltian ini menunjukkan seluruh responden yang tidak tamat SD mengalami gangguan fungsi kognitif ringan. Semakin tinggi tingkat pendidikan berhubungan dengan makin rendahnya kejadian gangguan fungsi kognitif.

Kelompok pasien yang tidak bekerja memiliki proporsi mengidap gangguan kognitif yang lebih besar dibandingkan pasien yang masih aktif bekerja. Individu dengan pendidikan dan sosioekonomi yang lebih tinggi memiliki fungsi kognitif yang lebih baik. Edukasi menimbulkan efek langsung pada struktur otak di awal kehidupan dengan meningkatkan jumlah sinaps atau vaskularisasi dan membuat cadangan fungsi kognitif, yang dikenal dengan teori "kapasitas cadangan". Selain itu, pendidikan di awal kehidupan memiliki pengaruh pada kehidupan ke depannya, yaitu timbulnya stimulasi mental untuk berpendidikan lebih tinggi lagi, yang memberikan dampak positif terhadap neurokimia dan menjaga integritas struktural di otak. ${ }^{14}$

Kebiasaan merokok dan berolahraga memiliki hubungan yang signifikan. Hubungan rutinnya mengonsumsi rokok dengan penurunan fungsi kognitif ditunjukkan pada kelompok yang memiliki kebiasaan merokok. Merokok pada usia pertengahan berhubungan dengan kejadian gangguan fungsi kognitif pada usia lanjut, sedangkan status masih merokok dihubungkan dengan peningkatan insiden demensia. ${ }^{15}$ Pasien yang tidak rutin berolahraga memiliki proporsi gangguan fungsi kognitif yang lebih banyak dibandingkan kelompok pasien yang rutin berolahraga. Hubungan antara aktivitas olahraga dengan kemampuan kognitif, terutama untuk

\section{Daftar Rujukan}

1. Rubattu S, Pagliaro B, Pierelli G, Santolamazza C, Castro SD, Mennuni S, dkk. Pathogenesis of target organ damage in hypertension: role of mitochondrial oxidative stress. Int $\mathbf{J}$ Mol Sci. 2014;16(1):823-839.

2. Whitworth JA. World Health Organization (WHO)/International Society of diamati pada kelompok lanjut usia. Individu yang memiliki rutinitas berolahraga memiliki kemampuan penalaran, fungsi eksekutif, ingatan, dan waktu reaksi yang lebih baik dibandingkan dengan individu yang jarang atau tidak pernah berolahraga. Jenis olahraga yang dianggap bermanfaat dalam mempertahankan fungsi kognitif pada orang tua antara lain senam aerobik, tenis meja, dan badminton. Sebuah penelitian di Minnesota mengungkapkan bahwa gerakan yang cenderung konstan dan berlangsung cepat seperti aerobik yang dilakukan selama 30 menit/ hari sebanyak 5 kali dalam seminggu terbukti berhubungan dengan pemeliharaan fungsi kognitif yang lebih baik. ${ }^{16}$

\section{Simpulan}

Kondisi hipertensi memiliki hubungan terhadap penurunan fungsi kognitif seseorang, semakin tinggi derajat hipertensi, semakin besar persentase penurunan fungsi kognitif yang dapat terjadi. Terdapat variabel-variabel lain, yaitu kelompok usia, jenis kelamin, pendidikan, pekerjaan, kebiasaan merokok, dan aktivitas olahraga yang memiliki pengaruh bermakna pada subjek penelitian dengan riwayat hipertensi terhadap gangguan fungsi kognitif.

\section{Konflik Kepentingan}

Laporan penelitian ini diajukan dalam sesi ilmiah presentasi poster di The Bali Neurology Update 5 th yang diselenggarakan oleh Perhimpunan Dokter Spesialis Saraf Indonesia cabang Denpasar bekerja sama dengan Fakultas Kedokteran Universitas Udayana dan Rumah Sakit Umum Pusat Sanglah Denpasar tanggal 22-24 September 2017 di Denpasar, Bali.

Hypertension (ISH) Statement on Management of Hypertension. J Hypertension. 2003;21(11):1983-1992.

3. Bell K, Twiggs J, Olin BR. Hypertension: The silent killer: updated JNC-8 guideline recommendations. Alabama Pharmacy Association. 2015;1-8.

4. Mallidi J, Penumetsa S, Lotfi A. Management of Hypertensive 
Emergencies. J Hypertens. 2013;2(117).

5. Riset Kesehatan Dasar (RISKESDAS). Badan Penelitian dan Pengembangan Kesehatan Kementerian RI tahun 2013.

6. Obisesan TO. Hypertension and cognitive function. Clin Geriatr Med. 2009;25(2):259-288.

7. Iadecola C, Yaffe K, Biller J, Bratzke LC, Faraci FM, Gorelick PB, dkk. Impact of hypertension on cognitive function: a scientific statement from the American Heart Association. Hypertension. 2016;68(6):67-94.

8. Gąsecki D, Kwarciany M, Nyka W, Narkiewicz K. Hypertension, brain damage and cognitive decline. Curr Hypertens Rep. 2013;15(6):547-558.

9. Goldstein FC, Levey AI, Steenland NK. High blood pressure and cognitive decline in mild cognitive impairment. J Am Geriatr Soc. 2013;61(1):67-73.

10. Borson S, Scanlan J, Hummel J, Gibbs K, Lessig M, Zuhr E. Implementing routine cognitive screening of older adults in primary care: process and impact on physician behavior. J Gen Intern Med. 2007;22(6):811-817.
11. Myers JS. Factors associated with changing cognitive function in older adults: Implications for nursing rehabilitation. Rehabil Nurs. 2008;33(3):117-123

12. Janicki SC, Schupf N. Hormonal influences on cognition and risk for Alzheimer's disease. Curr Neurol Neruosci Rep. 2010;10(5):359-366.

13. Luine VN. Estradiol and cognitive function: past, present and future. Horm Behav. 2014;66(4):602- 618 .

14. Lee S, Kawachi I, Berkman LF, Grodstein F. Education, other socioeconomic indicators, and cognitive function. Am J Epidemiol. 2003;157(8):712-720.

15. Sabia S, Elbaz A, Dugravot A, Head J, Shipley M, Hagger-Johnson G, dkk. Impact of smoking on cognitive decline in early old age: the Whitehall II cohort study. Arch Gen Psychiatry. 2012;69(6):627-635.

16. Gajewski PD, Falkenstein M. Physical activity and neurocognitive functioning in aging-a condensed updated review. Eur Rev Aging Phys Act, 2016;13(1). 